\title{
General Frame Work of New TQM Based on the ISO/IEC25000 Series of Standard
}

\author{
Kazuhiro Esaki \\ Faculty of Science and Engineering, Housei University, Kajino-cho, Koganei-shi, Tokyo, Japan \\ Email: Kees959@hotmail.com
}

Received April 8, 2013; revised May 15, 2013; accepted June 17, 2013

Copyright (C) 2013 Kazuhiro Esaki. This is an open access article distributed under the Creative Commons Attribution License, which permits unrestricted use, distribution, and reproduction in any medium, provided the original work is properly cited.

\begin{abstract}
Generally, for quality improvement of an organization management, TQM (Total Quality Management) is used worldwide and recognized. However, contents of activity are various, and it is difficult for organization to define the whole scope of TQM. It is very important that the activity theme about the TQM is based on the consideration of the needs and priority from the objective requirement, which should correspond to the basic consideration of quality management. If we have selected the wrong theme, and missed understanding about importance and priority of target for TQM, it may cause a significant risk in the organization management. For example, the company which got a high evaluation about the quality of management has poor management and disgraceful affair after several years, and it is a case reaching the bankruptcy. We worked on a study for improvement of technique for quality requirement and evaluation of system for many years, and have participated in the development of international standard for supporting the quality requirements and evaluation of system in ISO/IECJTC1/SC7. The organization having a specific purpose is a kind of system. It is thought that evaluation technique of the system quality is adaptive for a quality evaluation of the organization management. Therefore, this study suggests the new framework of TQM from the view point of the general framework of management defined in ISO/IEC25040 and TQM matrix. Furthermore, this paper presents the result of comparison between proposed action theme derived from a framework of new TQM and the example of existing TQM, and reports an inspection result of the effectiveness.
\end{abstract}

Keywords: TQM; Structure of Quality; TQM Matrix; Quality Assurance; Quality Improvement; Investment Management; Project Management; Static Risk Management; Dynamic Risk Management

\section{Introduction}

Generally, for quality improvement of an organization management, TQM (Total Quality Management) is used worldwide and recognized. The TQM has spread in USA in the 1990s, and to provide a high quality and suitable price of product and service at appropriate good timing for a customer satisfaction. In order to provide the best practice, TQM is the strategic system-like methodology to contribute to achieve the purpose of organization effectively. Not only one department but also the companies (a manager, a director, a worker, and others) and activity of QC are extended to "a design section, a production section, a purchasing section, a sales section, a marketing section and maintenance or service".

It is the system for company-wide quality control activities. The biggest aim is covering all processes from a plan, the design stage of the product to production, sale, maintenance, service and manages the quality of the product generally, and it is to aim at the effective and high quality management. As for the TQC, the principal objective is put for the quality improvement of the work process including the application to the indirect section whereas QC is an action coherent to the production spot.

TQM is the thing which improved the TQC more, and the characteristic for the activity is strategic and the top management should commit the total quality management and should lead top-down. The TQM clarifies requirements for the management quality of the organization by the examination standard for ex, American Malcolm Baldridge Prize [1] and Japanese management quality prize [2] etc. now. However, contents of activity are various, and it is difficult for organization to define the whole scope of TQM. It is very important that the activity theme about the TQM is based on the consideration of the needs and priority from the objective requirement, which should correspond to the basic consideration of quality management. If we have defined the wrong theme, 
and miss understanding about importance and priority of target for TQM, as a result, it may cause a significant risk in the organization management.

For example, the company which got a high evaluation about the quality of management causes poor management and disgraceful affair after several years, and there is the case reaching the bankruptcy. Such a situation has the risk to give many stakeholders concerned including the stockholder who misjudged a vast loss.

We worked on a study for improvement of quality requirement and evaluation of system for many years, and have participated in the development of international standard for supporting the quality requirements and evaluation of system in ISO/IECJTC1/SC7.

In recent years, we have been working on developing the ISO/IEC25000 (SQuaRE) series [3-8] of standards for quality requirements and evaluation for system and software product for a long time in ISO/IEC JTC1 (Joint Technical Committee 1 of the International Organization for Standardization and the International Electro technical Commission) SC7WG 6 (software and systems engineering under ISO technical committee, working group six).

As part of this project, we have worked on the developments of ISO/IEC25030, 25040, 25041 [6-8], which are the standards to provide supporting technology for the method of quantitative quality requirement definitions [6] and evaluation $[7,8]$ based on the ISO/IEC9126$1[5,9]$ quality model is widely recognized and used in world for the purpose of specify the quality requirement and evaluation of system/software product. On the other hand, definition of system is "a combination of interacting elements organized to achieve one or more stated purposes" defined in ISO/IEC15288: 2008 Systems and software engineering—System life cycle processes [10]. The organization having also a specific purpose is a kind of system, too. It is thought that evaluation technique of the system quality is adaptive for a quality evaluation of the organization management.

Therefore, this study suggest the new framework of TQM from the view point of the general framework of management defined in both proposed TQM matrix and elevation framework of ISO/IEC25040. Furthermore, this paper present the result of comparison between proposed activity theme derived from a framework of new TQM and the example of existing TQM, and report an inspection result of the effectiveness of proposed total framework of new TQM.

\section{Concept}

\subsection{Concept of Quality Improvement}

Figure 1 shows the concept of quality control that show the relationships between process and product, and con- cept of the PDC cycle. From Figure 1, every activity includes a product and a process. In addition, an input and output of process is included in the activity of organizations. Also, the quality control activity makes the repetition of product and process, which include a "productprocess-product-process and product” during a PDC cycle as shown in Figure 1. Output product of a process before becomes an input product for the later process. All kind of management processes is affected by an input quality of own process, which is a result of previous management process. Therefore, the quality of processes depends on a quality of previous process, and not to be able to exist alone each.

\section{-Definition of Quality}

From ISO, Terminology "Quality" is defined as "totality of characteristics of an entity that bear on its ability to satisfy stated and implied needs". Objects of a quality control usually are quality of product and quality of process. Furthermore, quality has both primary quality and second quality.

\section{-PDC Cycle}

It is necessary to turn the PDC cycle called the inspection to improve the quality of product and process to show in Figure 1. It should visualize a quality state of a product and process for turn a PDC cycle, and it is necessary to confirm the existence of problems. Generally, PDC is called PDCA as Plan-Do-Check-Action.

And, improvement activity should be performed immediately after checking and resolve the problems.

But "action" of improvement is same as "Do".

Therefore some kind of plan should be studied in front of the action because it is thought necessary. There is the risk that improvement activity leads to a change for the worse when we do not perform some kind of plan before improvement actions. Therefore, in this study, "PDCA" introduced "PDC".

\section{-Primary Quality}

It is to meet the requirements for the function that

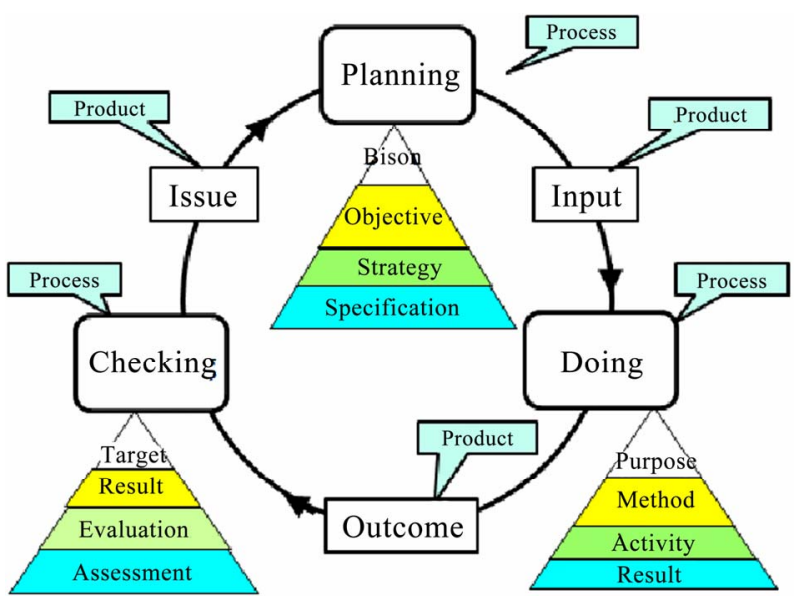

Figure 1. Concept of quality control. 
should be realized specified in a contract and a product specification, or it is to meet the business processes prescribed in quality or an international standard and a rule in the company. The un-satisfaction for primary quality requirement is a problem, and it is thought that the problem can be finally zero if we push forward correction essentially.

\section{- Secondary Quality}

It is an attractive quality to meet the tacit expectation of a customer needs. And the quality that we solve a problem having, and can be accomplished now. The issue is that a product and a process do not meet secondary quality. The problem never disappears as far as environment surrounding an organization changes. Therefore, it is necessary the solution to problem soaks a priority based on the need in order to be able to go ahead.

\section{-Product Quality}

The product is a product or service, result brought about as a result of input resources and activity of the organization activity, and there are the primary quality, secondary quality and quality in use.

When we define the quality of system product, the model of six quality characteristics of "functionality, reliability, efficiency, usability, portability, maintainability defined in ISO/IEC9126 and used a system product.

We show the influence that a product gives to a user with four quality characteristics such as "effectiveness, productivity, safety, satisfaction" as included in quality in use. "Quality at the time of the use" is quality of the use effect when it used a product in specific use purpose, environment, and it is the quality that a user finally feels by a product and a conformity degree of the use environment.

\section{-Process Quality}

The process is the process that converts input resources into the output, and it is a procedure or a method of the activity. We can regard the quality of process as efficiency to convert an input product in the organization activity into an output product. In ISO9001, are the requirements for the process followed with the quality of the process? Does a PDC cycle rotate?

We evaluate the attribute of the process and judge it.

Even if we measure the quality of process only, we cannot judge the quality of process. The quality of the process after the improvement is shown in a lower equation.

-Efficiency of process $=$ quality of outcome/input resource.

And evaluation of improvement degree of the process, it is necessary to evaluate that how improved for the quality of input resources essentially.

\subsection{Concept of the Structure of Quality}

Figure 2 shows the concept of "structure of quality problem and issue" by suggested in this study.

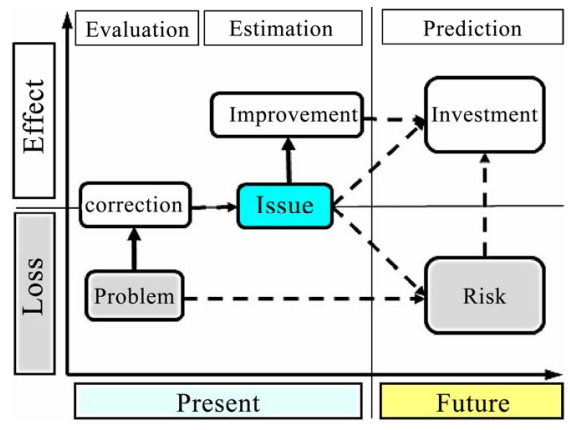

Figure 2. Concept of structure of quality.

The cross axle shows the present and the future in time axes, and the vertical axis shows a volume of positive effect or negative effect (a loss) by the influence of occurred problem.

It is necessary to correct problem in a normal condition immediately because the problem (the primary quality incompatible) that occurred in a product or process is in condition to have deviated from a plan and specifications during past or at present. And a negative effect (a loss) occurs when it take the influence of the quality in time, a vertical axis on the cross axle to show it in Figure 2.

As shown in Figure 2, the problem may cause a negative effect at present, and a more serious negative effect (a loss) will be at risk of the minus number to be connected in it. On the other hand, an issue (deficiency of the second quality) that occurred in a product or process is deviation from an attractive requirement actualized in the past or at present, and there is not the negative effect (a loss), but positive because it is not the deviation from a plan and specifications. Therefore, it is necessary to perform the solution based on the consideration of priority or importance and urgent degree of problem.

As shown in Figure 2, issue may cause big problem in future even if the issue does not have a negative effect (a loss) at present. On the other hand, the issue is actualized as a positive effect in the future when we make the improvement plan for expected positive effect and perform it. In this way, risk and investment management can be a necessary theme for TQM that is not a scope of quality control base on the structure of quality problem, and it is thought that should be intended theme for TQM.

\section{-Problem}

The problem is abnormal condition to have deviated from the normal condition should be. Following are example of problems.

-Trouble, an error, a defect, an obstacle (fault, obstacle), not conform.

\section{-Problem of Product}

Result of activity cannot realize the required plan or specifications with the deficiency of an actualized pro- 
duct.

\section{- Problem of Process}

It is that PDC does not rotate with the deficiency of an actualized process. The over budget that are not pushed forward in a planned schedule, delivery delay, incompatible. For example, it is not to meet the requirements of ISO9000 and the inner company rules.

\section{-Issue}

It is the actualized refinement that may bring improvement of the quality of a product and the process.

The outbreak probability of a certain phenomenon means the combination of results of the phenomenon.

\section{-Risk}

Probability of phenomenon and size of the damage when problem will occur.

\subsection{Concept of General Management Framework for Organization}

Figure 3 is the simplest concept of the organization activity that paid its attention to the specific process and product of the concept of the quality control that showed in Figure 1 and it is defined from the general framework of quality requirement and evaluation for system included in ISO/IEC25040. Furthermore, this framework is based on a concept of IDEF0 [11].

Figure 3 shows the product of four elements of new TQM and the management of the process.

In this study, the framework of the total quality management for improvement of the organizations quality is that the "input for, outcomes of, constrain for, own resources" and "the conversion process from input to outcomes" should included as shown in Figure 3.

The organization activity is regarded as a process to convert some kind of products (input resources) into some kind of products (Outcomes). In this study, "input, outcomes and resources" is called product, and "conversion procedure" is called process. It is important to control the organization activity effectively for quality con-

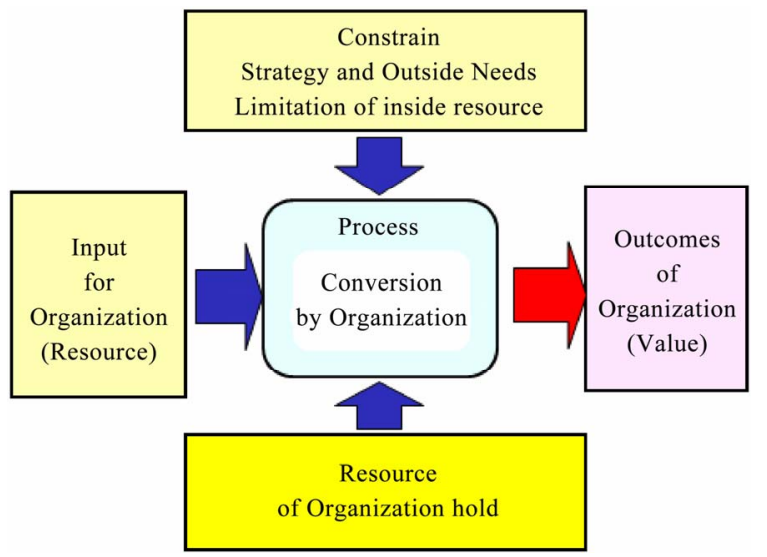

Figure 3. Frame work of quality evaluation. -ISO/IEC25040 (based on the IDEF0) [11]. trol forward. And, organization should produce high quality product (value and a product, service) from the view point of possible limited input and resources of organization own. In this study, I devised the theme of the organization management necessary to lead an organization to the success from such a viewpoint.

\section{Concept of the Total Quality Management Matrix}

Figure 4 shows the more detail and devised domain of new TQM framework, which has introduced based on the structure of quality problem as explained in Figure 2.

The time of the cross axle of Figure 2 can sort with the outbreak probability of the phenomenon more finely as shown in Figure 4. On the other hand, an effect and loss can define more detail in the vertical axis on a scale from the view point of influence of problem.

Based on the consideration of Figure 4, matrix of the whole object domain of the total quality management can be defined.

The domain of the total quality management has covered both quality assurance and quality improvement conventionally that has been intended. But, additional management such as investment (project management) and the risk management should cover from the view point of consideration of Figure 4. Figure 4 shows the four necessary domain of management for new TQM.

\subsection{Area of Quality Assurance}

\section{-Domain of the Quality Assurance.}

Activities of assurance of the primary quality of product and service that are specified and promised according to the contract of customers at past and present, and provide to customers. The activity of guarantee of quality corrects a problem shown in Figure 4, and should secure quality of normal state. For example, problem outbreak is such as violating of the contract, laws and ordinances or

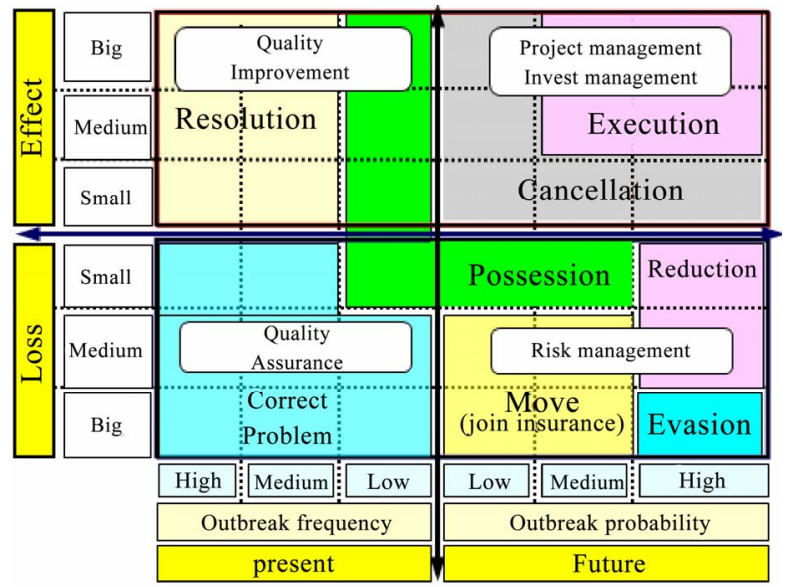

Figure 4. Concept of TQM matrix. 
a rule in the company. The activity to guarantee the quality of the products such as intermediate or final product and process such as the deficiency of the procedure of the specified plan, and aim of contract of customer should be achieved. Quality of output product and process should be achieved with the promised cost and the appointed date of delivery.

If result of activity could not come true according to the contract and the project plan, the problem should be corrected immediately. It is usually necessary to correct because the guarantee of quality responsibility (defect responsibility) based on the contract may cause a problem that occurred. And, it is necessary to correct problem promptly, because the problem has produces the negative effect (a loss). Correspondence of second quality is an improvement of the problems for the realization of attractive quality to satisfy the tacit expectation of the customer and is not included in a quality assurance.

If we cannot guarantee the primary quality of the product, the problem may occur after delivery to customer. When the worst, a recall may occur and asked the compensation for damages from a customer and continuation of the business is spoiled by loss of the trust of the organization. Therefore, a quality assurance is the required activities that perform surely in the organization. In addition, it is necessary to spread it horizontally so that not only correct a problem of merely activity but also avoid the same problem occurs in other projects and other organizations. Furthermore, provisional measures and permanent problem should be divided and should correct them. It is necessary to divide it into pieces for measures by consideration of the seriousness of the problem and an urgent degree, the skill of the personnel required, cost, the limitation of the period in provisional measures and permanency, and to carry it out.

\subsection{Area of Quality Improvement}

-Domain of the Quality Improvement

It is a domain of the quality improvement such as the QC (Quality Control) circles which have been performed conventionally. That activity solves the issue that an organization holds, and to raise it in attractive quality of product of the organization and the second quality of the process, and to meet an expected requirement. The issue does not produce the negative effect at that point, but may cause positive effect, if we can improve it. We cope the improvement issue actualized in the past or at present that an attractive quality of product or the more effective procedures. The issues may be changed by the application environment of the result.

And it is necessary to consider the priority while ascertaining advancement of the aim, reduction in cost, strength and emergency degree of the demand of customer including shortening on the appointed delivery date because defect responsibility does not necessarily occur, and to cope. We can hit a priority in consideration of the importance, emergency degree and can go ahead through the improvement only when we evaluate the effect that we can expect when we solve the issue by the improvement. The remaining problems are limited as far as there is a contract with customers, but issue may not always disappear. The improvement of the secondary quality is an everlasting theme of the quality control.

\subsection{Area of Static Risk Management}

\section{—Domain of Static Risk Management}

It is a domain called risk management conventionally.

It may cause future problem by the influenced from a product (the intermediate, final) or the process (the deficiency of the requirement procedure) of the present organization and is generally called as risk management.

Risk is defined as the scale of the damage and probability that a problem will produce in future when occurred.

It may cause big problem for organization in future, if we leave a present hold problem when do not take any improvement actions and may lay a negative effect (a loss). When we do not hit any measures and improve the present conditions, it is a problem that will occur in future by the turn of inside situation or change of outside environment of organization, and this case has called "static risk” in this study. We investigate a risk to be inherent in a product and a process of the present based on correspondence of policy, risk analysis to a static risk and, by risk assessment, calculate the outbreak probability and scale of the damage at the time of the outbreak quantitatively and estimate it. In addition, as for the risk measures, it is necessary performing based on the consideration of the priority from the effectiveness and limited input resources, and to perform "reception, imputation, reduction and evasion” four risk measures correspond to the result of risk analysis as the TQM matrix as shown in Figure 4.

\subsection{Area of Investment Management}

\section{—Domain of the Investment Management}

The domain of the quality of the investment activity, it is a domain called the project management or investment management conventionally. The management of the investment risk is generally handled as risk management of the projects out of an object of the quality management in PMBOK [12]. The project can be called the investment activity to get a positive effect to expect in the future. Therefore, the project management can be called the management of the investment risk, because risk may be caused by the activity of project.

Investment management should be included in the 
TQM, because that should achieve a current quality problem or issues for taking the expected positive effect (value) in the future. In this study, the degree of the "positive or negative effect" that is caused by the influence from project when we hit the measures expecting improvement in future, investment management risk can be called dynamic risk. From Figure 4, the dynamic risk is defined on the "probability and scale of an effect" when it occurred by the project which produce an expectation or negative effect by taking new action for improvement. Inherent risk of project for a purpose and the accomplishment of a project described in the plan should be estimated at the planning before project start.

From Figure 4, it is necessary for the risk management to perform judgment such as enforcement or avoidance from the view point of success probability and the cost-effectiveness in response to the result of risk and the portfolio analysis as a general rule.

\section{Total Quality Management Framework}

Figure 5 is the overall framework of the new TQM which is introduced from a concept of both Figures 3 and 4 suggested. From Figure 5, "input resources, outcomes and each domain of management process" has systematized. Furthermore, Figure 5 shows the framework of whole TQM, which include such as the input for, outcomes, constrains and a supporting resources for organization activity and conversion process from input into the outcomes. The risk management of project and investment management have been handled as the specific management theme and out of scope of TQM.

But, in this study, management of risk of project and investment can be the important theme of TQM, and should be included in the domain of TQM from the consideration of TQM matrix as shown in Figure 4.

From Figure 5, input for the organizations may be the demand from various stakeholders which occurred in the

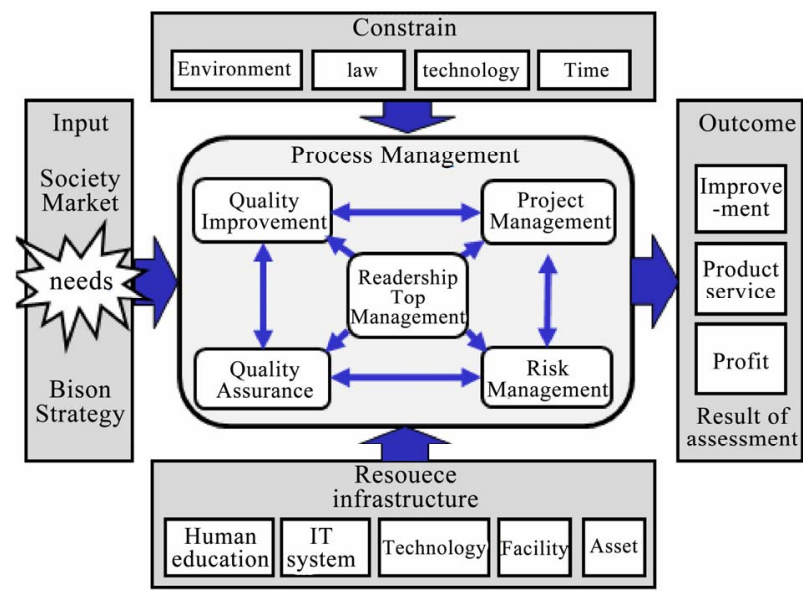

Figure 5. Total frame work of TQM. external environment of the organization. Furthermore, the outcome is the result of organization activity.

The organization activity is carried out with input resources in the line of the factory and the specific environment of work, and as the result, product and service has be provided. In addition, as the secondary effect, it produces various improvement effects or brings the negative effect except organization purposes such as the discharge of the $\mathrm{CO}_{2}$. The improvement includes the wide meaning for various for products such as input and outcomes. And discharge of $\mathrm{CO}_{2}$ can be recognized as the negative improvement effect.

First, constrain is the demand for the organizations that include aim, budgets and time limit of which agreed with customers. Second, constrain include the limitation such as law, rule, standard, corporate strategy of the organization, financial resource, human resource, facilities environment and technologies to support the organization activities. The resource of organization is the supporting infrastructures that include the various management technology, financial resources, information system and human resources etc.

In this study, I have proposed the new framework of $\mathrm{TQM}$, that is necessary to lead an organization for success of improvement from such a viewpoint and considerations.

\subsection{Management of Input}

The input is the new resources need to adopt from the outside necessary for organization activity as follows.

-Demand from customer, human resources, facilities, materials, engineering, technique necessary for the demand from the customers, etc.

\section{-Demand from Customer}

It is grounds to determine the necessity of the organization activity, and the grasp of the demand from customer is important to identify a purpose of the organization strategy management and the plan management. The demand is the time limit of activity, customer's expectation of quality and quantity of the cost, etc. Demand of customer is the both agreed "demand stated clearly" and "the potential demand" that is the "implicit demand". We should grasp it through a requirements definition process with customer. And the necessary demand from customer should be defined in to incorporate the aim of organization planning appropriately.

\section{-Human Resources}

The human resources are the main subject of the organization activity. Quality improvement and the efficiency of the organization activity depend on the quality of human resources greatly. The human resources is the only existence having the thing true to make a value, and it is an organization comprised by the personnel required 
and workers. In addition, the organization is formed by the human resources based on some purpose of existence ideas. Human resources should have the ability and specialty that adapted to the every process of organization management from the demanded. For the purpose of achievement of organization successfully, procurement of the human resources should be performed based on constrain from organization strategy.

\subsection{Management of Outcomes}

Quality management is the activity for the quality of result of "product or service, and improvement of process" by performing TQM for the purpose of improvement as shown in Figure 5.

\section{-Economical Result}

The output of the process is the result of "profit, sales, cost reduction, cash flow and asset" by total quality management activity as shown in Figure 5. The information such as profitability or productivity, cause or measures that occurred by a process of activity of organization are included.

\section{-Result of the Organization Activity}

The output of the process is the result of "quality of product or service, and improvement of process" by total quality management activity as shown in Figure 5.

The information such as problems or issues, cause or measures that occurred by a process of activity of organization are included. The result of process such as "product quality, appointed date of delivery and the cost improvement defined in the plan as aim" may be achieved finally by using these quality related information. It is the aim of activity that should be accomplished by tissue, and the aim should be achieved.

The product should be popular in the world, and value is broken into by you, and advantage is provided.

The result of quality in use may be different in response to a demand of customer's needs. The result of application effect may the result of "direct or indirect improvement" provided by the organization. The characteristic of direct result is the characteristics of new product developed and information system introduced, etc.

The characteristic of effect is the improved work process of organization, the expansion of the sales provided by the injection of new product to the market, result of improvement of productivity and business efficiency based on the installed new information system, improvement of the profit, etc.

\section{-Effect of Improvement (Kaizen)}

An object of the improvement has the outcome (a product or service) and the process of organization.

The effect of improvement is the degree of improvement of human skill, the quality of input and outcomes, result of the process improvement of organization.

\subsection{Management of Constrain}

-Constrain of the Organization Activity

It is led by "laws, Corporate strategy, inner companies laws, regulation, demand" from the outside of organization. Also led by the limitation of resources such as "financial resources, human resources, facilities, material, and technique" of organization. It is the limitation included in an aim set to an organization plan. And the example of elements are the "purpose, delivery date, planned budget of project" and strategy of organization, etc.

\section{-Strategy of Organization}

They have the inseparable relationship between corporate strategy and the process activities of organization.

It is necessary to draft the organization strategy of the organization as a premise of the organization activity.

The organization activity is placed in the low rank of the corporate strategy and influenced by the limitation of corporate strategy.

\section{-Financial Resources of Organization}

The organization activity has the limitation by financial resources of organization. For example, the human resources of company have an influence on the success or failure of the organization activity very much. And, lack of human resources may cause the failure.

\section{- Technique of Organization}

The organization activity has the limitation of technology of organization. For example, technique, method, tools, management standard, management style of supporting, management rule and a standard procedure, etc.

The limitation of the management support technology has an influence on the success or failure of the organization activity very much. And, lack of technology may be big limitation of the organization activity.

\section{- Laws and Ordinances, Regulation}

Laws and ordinances are applied to control organization activity. And, such elements are internal law and rule, a product standard, an international standard, the office rule that organization activity should obey. ISO9000 and the Labor Standards Law is recognizes applied law and rule, and it is necessary to obey it surely.

\subsection{Management of Resources}

It is the support base which an organization helping practice of the organization activity holds. Examples of elements are information system, financial resources, human resources, facilities, material and core technology, etc.

-Financial Resources Which an Organization Holds

The organization activity that a company organization carries out is affected by the financial resources which the organization holds. For example, the human resources that a company holds have an influence on the suc- 
Table 1. Comparison of total quality management.

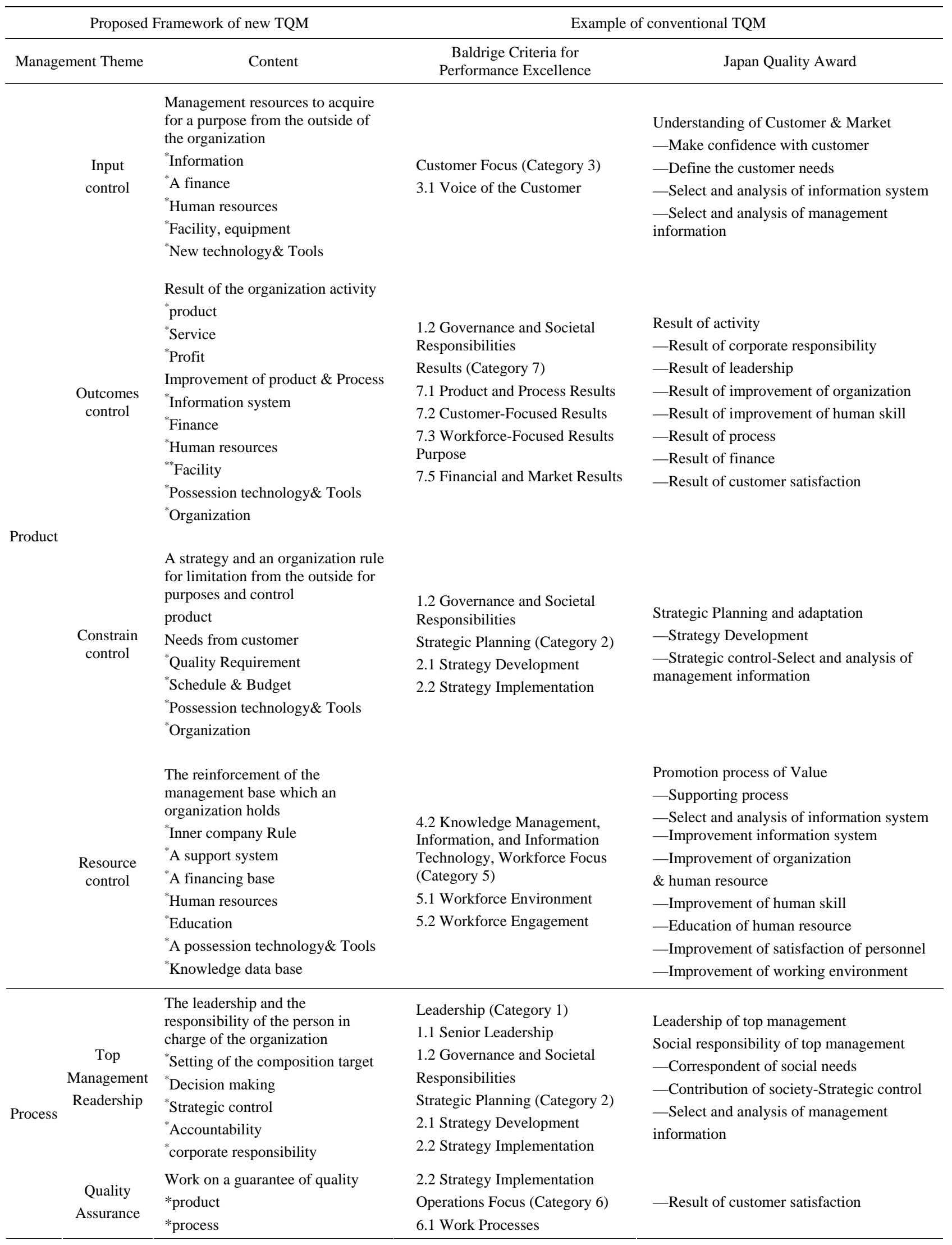




\begin{tabular}{|c|c|c|c|}
\hline \multirow{6}{*}{$\begin{array}{c}\text { Quality } \\
\text { Improvement }\end{array}$} & & $\begin{array}{l}\text { Measurement, Analysis, and } \\
\text { Knowledge Management (Category 4) }\end{array}$ & \multirow{6}{*}{$\begin{array}{l}\text { Process of Value promotion } \\
\text { — Business process improvement } \\
\text { —-make confidence with customer }\end{array}$} \\
\hline & $\begin{array}{l}\text { Quality improvement activities } \\
{ }^{*} \text { A product }\end{array}$ & $\begin{array}{l}4.1 \text { Measurement, Analysis, and } \\
\text { Improvement of Organizational } \\
\text { Performance }\end{array}$ & \\
\hline & $\begin{array}{l}\text { A person, a thing, money, } \\
\text { information } \\
{ }^{*} \text { A process }\end{array}$ & $\begin{array}{l}\text { 4.2 Knowledge Management, } \\
\text { Information, and Information } \\
\text { Technology }\end{array}$ & \\
\hline & \multirow[t]{3}{*}{ A procedure, a method, rules } & Operations Focus (Category 6) & \\
\hline & & 6.1 Work Processes & \\
\hline & & 6.2 Operational Effectiveness & \\
\hline $\begin{array}{c}\text { Risk } \\
\text { management }\end{array}$ & $\begin{array}{l}\text { Static risk management to reduce a } \\
\text { negative effect }\end{array}$ & --- & ---- \\
\hline \multirow{4}{*}{$\begin{array}{l}\text { Investment } \\
\text { Project } \\
\text { management }\end{array}$} & $\begin{array}{l}\text { Dynamic risk management in hope } \\
\text { of a positive effect }\end{array}$ & \multirow{4}{*}{----} & \multirow{4}{*}{----} \\
\hline & ${ }^{*}$ Investment management & & \\
\hline & ${ }^{*}$ Project management & & \\
\hline & "Finance investment & & \\
\hline
\end{tabular}

cess or failure of the organization activity very much.

And human resources and the facilities become the big support factor of the organization activity.

\section{-The Technique That an Organization Holds}

A theory and the technique are utilized for the purpose of quality improvement and efficiency of the organization activity. A technique for the organization management is necessary to let an organization succeed.

The possession of technology becomes the big support factor of the organization activity. It is necessary to identify a necessary thing from the plan stage of the organization, and to introduce it to vary according to the process of the organization management.

\section{-Support Information System}

The organization activity is supported by introduced information system.

\section{Verification}

Table 1 shows the result of comparison between evaluation criteria of new TQM that has proposed in this study and evaluation criteria of other conventional TQM.

From Table 1, quality control of forward investment activity and the risk management for the future is thin in the conventional TQM is recognized.

Furthermore, it is thought that "the management of input, outcomes, constrain and resource" is weak based on the result of Table $\mathbf{1}$ from the view point of new TQM framework proposed in this study.

Input resources limited as for the good TQM is given, and, as a result, under the limitation condition, how much value can provide? TQM is the relative quality of efficiency to say how much improvement you can bring about. And, for the purpose of true improvement of organization management quality, not only improve process management but also improvement of "input, outcomes, constrain and resource of the organization" of organization should be performed.

\section{Conclusions}

In this study, I suggested the theme that it was necessary to really perform it in TQM from the viewpoint of the framework of the new TQM for an activity theme of the TQM which had been pushed forward conventionally as shown in Figure 5. From the result of the comparison of Table 1, the activity of forward investment and the risk management for the future seems to be short in the conventional TQM. Therefore, we should cope with the spatial and time turn of events of the outside of organization when you would like to provide suitable for the sustained development of the organization and will offer the continuous stability-like value to a customer.

Based on a framework of new TQM, it is thought that the reinforcement of the action for forward investment activity (like project management or innovation) and the risk management that stood in the long term prospects is necessary as well as a short term.

In addition, in the TQM, we should manage the improvement of quality of "input, outcomes, constrain, resources", and it is thought with the theme that is extremely important to the reinforcement of activity improving. And it is thought that it is important to evaluate how much you laid the result from limited input resources. In the framework of new TQM shown in Figure 5, I put the leadership of top management in the center of Figure 5 and locate quality assurance, quality improvement, risk management, investment management in the circumference. It is thought that mind about values of the top leader is very important located in the center of the TQM. 
The leadership of top management is extremely important for the improvement of management quality.

If the quality of top management is bad even if the management system of organization is good, we cannot continue to supply the good outcome such as product or service. As a result, it is thought that we cannot secure the consequent profit.

In the future study, the author plans to study the evaluation indicators of management quality of organization by each theme proposed in this study and would like to verify of them.

\section{Acknowledgements}

The authors are grateful to members of production system research office at Graduate School of Factory of Science and Engineering HOSEI University who their contributions and support to make the discussion.

\section{REFERENCES}

[1] American Malcolm Baldridge Prize, Criteria for Performance Excellence, 2014.

http://www.nist.gov/baldrige/publications/business_nonpr ofit_criteria.cfm/

[2] Japanese Management Quality Prize, Criteria for Performance Excellence. http://www.jpc-net.jp/eng/award/

[3] ISO/IEC25000, "Software Engineering-Software Product Quality Requirements and Evaluation (SQuaRE)—Guide to SQuaRE,” International Organization for Standardiza- tion, 2005.

[4] ISO/IEC25001, "Software Engineering-Software Product Quality Requirements and Evaluation (SQuaRE) - Planning and Management," International Organization for Standardization, 2007.

[5] ISO/IEC25010, "Software Engineering-System and Software Quality Requirements and Evaluation (SQuaRE)System and Software Quality Model,” International Organization for Standardization, 2011.

[6] ISO/IEC25030, “Software Engineering-Software Product Quality Requirements and Evaluation (SQuaRE)—Quality Requirement,” International Organization for Standardization, 2007.

[7] ISO/IEC25040, "Software Engineering-System and Software Quality Requirements and Evaluation (SQuaRE)— Evaluation Process,” 2011.

[8] ISO/IEC25041: "Software Engineering-System and Software Quality Requirements and Evaluation (SQuaRE)Evaluation Guide for Developers, Acquirers and Independent Evaluators,” 2012.

[9] ISO/IEC9126-1, "Software Engineering-Product Quality —Part1: Quality Model,” 2001.

[10] ISO/IEC15288, "Systems and Software Engineering System life Cycle Processes-System Life Cycle Processes,” International Organization for Standardization, 2008.

[11] Federal Information Processing Standards Publication 183, Integration definition for Function Modeling (IDEF0), 1993.

[12] Project Management Body of Knowledge, 4th Edition, Project Management Institute, 2008. 